Article

\title{
Quantitative Analysis of Key Performance Indicators of Green Supply Chain in FMCG Industries Using Non-Linear Fuzzy Method
}

\author{
Hamed Nozari ${ }^{1}$, Esmaeil Najafi ${ }^{2} * \mathbb{E}$, Mohammad Fallah ${ }^{1}$ and Farhad Hosseinzadeh Lotfi ${ }^{3}$ \\ 1 Department of Industrial Engineering of Central Tehran Branch, Islamic Azad University, Tehran \\ 1469669191, Iran; ham.nozari.eng@iauctb.ac.ir (H.N.); Mohammad.fallah43@yahoo.com (M.F.) \\ 2 Department of Industrial Engineering of Science and Research Branch, Islamic Azad University, \\ Tehran 1477893855, Iran \\ 3 Department of Mathematics of Science and Research Branch, Islamic Azad University, Tehran 1477893855, \\ Iran; hosseinzadeh_lotf@yahoo.com \\ * Correspondence: e.najafi@srbiau.ac.ir
}

Received: 20 September 2019; Accepted: 24 October 2019; Published: 27 October 2019

\begin{abstract}
Nowadays, along with increasing companies' activities, one of the main environmental protective tools is green supply chain management (GSCM). Since fast-moving consumer goods (FMCG) companies are manufacturing materials that usually require special warehousing as well as different distribution systems, and since companies of food products tend to fall into this area, the safety of their manufactured materials is a vital global challenge. For this reason, organizations in addition to governments have realized the importance of the green supply chain in these industries. Therefore, the present study examines the key performance indicators (KPIs) of the green supply chain in the FMCG industry. There are several performance indicators for the green supply chain. In this study, the KPIs were extracted based on the literatures as well as the opinions of experts through which key indicators in FMCG industries were identified. Using the fuzzy decision -making trial and evaluation laboratory (DEMATEL) method, the relationships and interactions of these key indices were determined. Moreover, a fuzzy nonlinear mathematical modeling was used to investigate the significance of these indicators. It is revealed that the organizational environmental management factor has the highest priority.
\end{abstract}

Keywords: performance management; green supply chain; decision making; nonlinear mathematical modeling; FMCG industries; fuzzy DEMATEL

\section{Introduction}

Recently, due to growing consumers' demands for green products without harming the environment, the concept of green supply chain has emerged. The green supply chain not only includes environmental consciousness in business, it also guarantees the sustainable development of industries. To this end, various measures have been taken by governments and organizations to address this issue [1]. These include enforcing green laws and using eco-friendly raw materials, reducing the use of fossil and petroleum resources, recycling papers, reusing waste, etc. in organizations. The successful adoption as well as accomplishment of green ideas in supply chain business activities is such that its prospects are not easily visible. Therefore, the activities and products of the green supply chain are at different risks [2]. For this reason, accurate management and understanding of the green supply chain is of paramount importance and it will be necessary to focus on developing useful responsibilities and strategies that are effective in successfully implementing the green supply chain. Organizations help to control green supply chain risks by reducing waste, evaluating suppliers based 
on environmental performance, increasing production of environmentally friendly products, and other performance parameters related to green activities [3]. Optimizing the amount of energy used in the product life cycle has also become a very important issue for organizations [4]. Because of the importance of the subject as well as raising the general awareness of technologies applied in production and distribution of products in addition to the importance of goods produced in the FMCG, it seems a fundamental need to use green methods in the supply chain. It is widely recognized that the FMCG represents a key industry to provide an enormous volume of human daily demanding in which all individuals not considering the age, gender and boundaries are involved. The FMCG industry mainly consists of processed foods, prepared meals, beverages, fresh or frozen and dry foods, medicines, cosmetic products, and other non-durable products. Due to the size of this industry, its greener supply chain can lead to sustainable development and meeting the environmental standards. For this reason, green supply chain managers at leading companies in the FMCG industry strive to utilize green logistics and improve their environmental performance throughout the supply chain as a strategic weapon to gain competitive advantage [5]. Therefore, understanding the types and evaluation of KPI to improve the performance of the green supply chain can be extremely important research on this area. However, always exploring green solutions in different industries individually can be an effective way to make the industry more successful. It may be noted that there is little research that focus on KPIs for the implementation of green supply chain and no work has been done in foods and pharmaceutical parts of FMCG industries as the main sectors of these industries. Moreover, the concept of KPIs in green supply chain of the FMCG industries in Iran has not been academically investigated yet and as one the most important supply chains, it should be considered to be a major concern.

In this regard, the current study has attempted to evaluate key indicators of performance for green supply chain in FMCG industries (here are exclusively food and pharmaceutical industries). To this end, first, literature on the subject is briefly reviewed and then the key indicators affecting the green supply chain in these companies is extracted based on the literature as well as utilizing the views of experts. Afterwards, using the fuzzy decision method, the internal effects of these indicators are investigated and finally, these indicators are prioritized by using nonlinear fuzzy modeling, as a fuzzy analytic hierarchy process (AHP)-based method that was easy to use, despite the complexity and nonlinearity of the constraints. The rest of the paper is organized as follows. Section 2 presents a review of the literature in terms of FMCG industries and green supply chains. Section 3 presents the green supply chain KPIs. Section 4 illustrates the MCDM and non-linear fuzzy mathematical modeling to analyze the KPI. The obtained findings will be discussed in Section 5, and lastly, the conclusions are presented in Section 6.

\section{Literature Review}

In order to assess KPIs of green supply chain systems in foods and pharmaceutical industries of FMCG sectors, a brief review regarding FMCG industries as well as green supply chain have been presented.

\subsection{FMCG Industries}

FMCG refer to those products that are sold rapidly at a rather low cost case of low margin-high volume [6,7]. The FMCG industry trades in commodities that are classified as essential products [8]. Typically, FMCG consist of non-durable products that are not limited to general groceries, beverages and beauty, skin care, and cosmetics. However, we focus on the FMCG supply chain in foods and pharmaceutical components as an application example.

The FMCG industry comprises a big part of budget of consumers in all countries [9]. The level of involvement can further be considered as how serious a consumer is in purchasing a product and how much information they require during their decision-making process. Therefore, a functioning retail sector is crucial for daily provision of essential products at high quality and low cost [10]. Thus, since many people are frequently buying these products, the cost that households pay for 
FMCG product categories is very significant, in light of the fact that products in the FMCG industry are short-lived and highly manufactured in terms of volume and variety. Therefore, there is an increasing pressure on retailers to simultaneously control cost and improve customer service [11] while reducing the environmental impact of their activities [12]. The FMCG industry primarily focuses on manufacturing, packaging goods, distributing, and some of fundamental activities including sales and marketing, financing, and purchasing [13] and it is found that the share of the FMCG industries in gross domestic product (GDP) is significant [14]. In the last few decades, the FMCG supply chain has faced more challenges due to increasing a tendency towards more demanding service level leading to higher delivery frequencies with smaller shipments sizes and consequent fragmentation of flows [11]. In addition, the FMCG environment is unpredictable and known as the most difficult part of the boom because commodities look similar without real competitive advantage and consumers tend to place a lot of values on different brands. In this industry, competition between competitors is always fierce, and the battle for market share continues [15]. Therefore, efforts for increasing the efficiency level of the FMCG supply chain have been undertaken with alternative transport solutions such as intermodal transport [16]. Colicchia et al. [9] investigated how intermodal transport in the Italian FMCG can be adopted for managing a lean and green supply chain by proposing a scenario-based estimation tool of the potential demand for intermodal transport. Singh and Acharya [17] identified supply chain flexibility dimensions from literature and field survey and they applied DEMATEL method to evaluate the flexibility dimension in Indian FMCG sector. Craggs [18] studied the impact of GSCM in the South African FMCG sector by presenting a "green supply chain maturity assessment questionnaire" as a potential answer to this need. Schoeman and Sanchez [19] investigated status quo concerning the environment and the human impact on its sustainability emphasizing on the green supply chain in FMCG industries in South Africa.

The green supply chain approach seems particularly relevant to the FMCG sector where identifying the performance indicators can potentially ensure significant benefits. Therefore, it is necessary to investigate the challenges factors and KPIs of foods and pharmaceutical companies with the consideration of green supply chain perspective.

\subsection{Green Supply Chain}

The rise of government regulations to meet environmental standards and growing consumer demand for green products has led to the emergence of the concept of GSCM, which encompasses the product life cycle from design to recycling. In recent years, GSCM as a significant approach for enterprises to be environmentally sustainable has attracted lots of attentions within both academia and industry. Among these industries, FMCG ones especially those related to foods and pharmaceutical, involves some crucial functions such as procurement, production, processing, and storage in the intermediate and final phases. In order to improve the competitiveness and profit, it was proved that supply chain management integrates internal operational activities with external customer demands [20]. Additionally, it was revealed that GSCM is the process of incorporating environmental criteria into business activities and the main point in supply chain greening is that it starts with establishing demand for greener products [21]. It was also indicated that the success of GSCM initiatives depends on proactivity and communion among supply chain members to ensure that environmental impact of the manufacturing and delivery of products and services is minimized [22]. Acevedo [23] examined contributions of interdisciplinary research to understanding interactions between environmental quality, food production, and food security. It was perceived that linking the geospatial, biotechnological, and precision agriculture technologies with the implemented models leads to achieving sustainable food production increases that maintain environmental quality. Dharni and Sharma [24] studied the status of supply chain management in food processing industry of Punjab state of India. It was revealed that logistics and supply chain management is still in its infancy in food processing sector in addition to not considering as a separate area of management. Gardas et al. [25] applied an interpretive structural modeling approach to establish the causal factors of the 
post-harvesting losses in the Indian context. They found that the lack of linkages between industry, government, and institution is the most significant factor. Liang et al. [26] indicated that it is crucial to evaluate the performance of GSCM in the entire supply chain. Akkerman et al. [27] reviewed quantitative operations management approaches to food distribution management, and relate this to challenges faced by the industry.

The main activities in GSCM are considered as green design, green purchasing, green manufacturing, and green transportation, which have attracted lots of attention in studies. Green design aims to design the products with enhanced biological quality that minimizes the harmful effects on the ecosystem [28,29], green purchasing presents procurement of environmentally preferable products and services [30-32], green manufacturing is introduced as a manufacturing process leading to lessening environmental impact [33-35], and green transportation refers to those ones that do not depend on diminishing natural resources [36]. Lin [37] investigated the criteria that affect GSCM practices-namely practices, performances, and external pressures—to raise awareness of environmental protection through green design, green purchasing, etc. Moreover, von Malmborg [38] argued that an environmental management system can be understood not only as a technical tool for analytical management but also as a tool for communicative action and organizational learning. Carpitella et al. [39] discussed organizational risk assessment in industrial environments by employing decision-making trial and evaluation laboratory method. Zhu and Sarkis [40] declared that GSCM tended to have win-win relationships in terms of environmental and economic performances in addition to providing an insight into the growing field of the relationship between environmental and operational practices and performance. They applied modified hierarchical regression methodology to test the various hypotheses. Chung et al. [41] examined the relationships between internal green practices, external green integration, green performance, and firm competitiveness in container shipping. Zhu et al. [42] investigated the correlation of major factors including organizational learning and management support for adopting GSCM. In order to compare organization characteristics of the two groups of respondent manufacturer, they employed Chi-Square test. Chung and Wee [43] developed an integrated inventory model with green component life cycle value design and remanufacturing considering the relevant price once implementing JIT delivery. Moreover, they implemented sensitivity analysis on the proposed time-weighted inventory deteriorating model. Yeh and Chuang [44] introduced some green criteria and developed an optimal arithmetical designing model for green partner selection including value, time, merchandise quality, and green appraisal score. Saif and Elhedhli [45] modeled the cold supply chain design problem as a mixed-integer concave minimization problem with dual objectives of minimizing the total cost-including capacity, transportation, and inventory costs-and the global warming impact through the use of a hybrid simulation-optimization approach. Bhateja et al. [46] discussed various environmental factors affecting in the manufacturing sectors and help them assess green future by considering GSCM including 17 indicators and 33 sub-indicators in which survey based on questionnaire has been utilized to collect data. Toke et al. [47] examined the measurement model of GSCM practices implementations focusing on 19 performance measure factors and applied AHP for determining relative importance and selecting appropriate approach in GSCM practice. Sharma et al. [48] suggested 13 indicators and 79 sub-indicators for implementation of GSCM in agro industry in which the quantitative phase was carried out through a survey using standard questionnaire with various agro based companies. Considering mentioned researches, it may be noted that there are still a few number of investigations that concentrate on KPIs for the implementation of GSCM and no work has been done in foods and pharmaceutical parts of FMCG industries.

\section{Green Supply Chain KPI in FMCG's}

The KPIs were explored within reviewing the literature on GSCM as well as in-depth interviews with FMCG industry experts. The expert team consisted of 18 specialists of supply chain FMCG considering foods and pharmaceutical companies in Iran and 7 university professors of supply chain 
management department. Then, through reviewing the literature and after discussion with experts, 12 KPIs have been identified and expressed as follows:

- Green purchasing; Since customer demands for environment-friendly or green products is increasing, green purchasing concentrates on cooperation from the suppliers to develop these eco-friendly products. Green purchasing is concerned with using eco-friendly raw materials, reuse of materials, recovery of waste, green management practices, green production processes, etc. to integrate their environmental goals. Moreover, some sub-indicators in green purchasing can be considered such as supplier's environmental management system, eco-labeling products as well as enough eco-labeling information for consumers and collaboration with suppliers and vendors for environmental targets. In addition, increasing recyclable packaging by suppliers in order to meet the desired health and environmental objectives.

- Green manufacturing; It focuses on environmental friendly procedures alongside energy efficient technologies through manufacturing stage of products. So, some certain environmental consciousness, for instance decreasing the energy consumption, employing efficient environmental management plans, etc. is considered in green manufacturing. Furthermore, some sub-indicators can be included such as system for waste minimization, impact of green manufacturing on brand image, following 3Rs-i.e., Recycle, Re-manufacture, Reuse-in addition to reduction in material cost after performing green procedures.

- Green design; It refers to design issues considering the choice of raw material, pollution prevention, design of packaging as well as redesign, conservation of resource and waste management. Additionally, life-cycle analysis is significant in view of green design concept. So, it is considered to minimize the material and energy consumption, recycle the components in addition to decreasing the usage of hazardous and toxic materials. Moreover, product designing for storage area during the transportation is should be taken into account.

- Green transportation; it refers to strategies for reducing transportation and warehousing cost as well as improving the environmental performance, considering various aspects such as sources of pollution in addition to diminishing level of fossil fuel and dependency on oil energy. Considering the effect of material, shape, and size of packaging in transportation, reducing packaging material and standardizing packaging which leading to transportation cost reduction are some of sub-indicators that can be considered in this level.

- Organizational environmental management; The engagement of greatest management supporting by other employees are really important to effectively implement the GSCM. There can be some sub-indicators in this category such as considering systems to track environmental laws and directives, documented procedure to implement curative action plan in addition to top and middle level management commitment for GSCM.

- Collaboration between customers and suppliers; A cooperation between suppliers and customers in addition to involving vendors in design phase of GSCM is an essential factor to improve the quality of the products. Furthermore, sharing of GSCM objectives with suppliers and vendors as well as having a structure of information sharing with suppliers and consumers can be considered in this indicator category in addition to taking collaboration from customer for greener production as well as green purchasing into account.

- Environmental performance; It refers to the capability of an organization to minimize various types of pollution and reduce the consumption of toxic substances. As sub-indicators, ability of GSCM to diminish emissions, effectiveness of the system to reduce water and solid pollutants, in addition to the extent to which GSCM reduces harmful material can be considered.

- Economic performance; It correlates to the economic improvement reflecting through the cost reduction in material purchasing, cost reduction connected with penalties for environmental accidents, energy consumption by GSCM as well as waste treatment and discharge. Furthermore, 
it should be noticed that whether GSCM create quest for innovation and has GSCM increased income for the company?

- Operational performance; It refers to the enterprise's ability in order to efficiently produce and deliver the products to the customers, considering the number of products that timely delivered, decreasing scrap rate and inventory levels. Improvements in capacity utilization after GSCM implementation in addition to increased brand loyalty by consumers are some sub-dedicators that should be taken into account. Moreover, it should be noticed that up to what extent GSCM can enhance public relations.

- Competitive pressure; In light of the competitive marketplace, it is essential for organizations to grab the particular product's environmental impact through the implementation of the green practices. Some subsets including extent to which brand image is a major concern, effect of green schemes of competitors to implement GSCM and increase in interest of top managers by competitive green practices can be taken into account in this KPI.

- Regulatory pressure; The pressure from the government, customers and the stockholders is needed for the adoption and accomplishment of GSCM. Therefore, policies of the state government play a significant role in organizations to start up with green commencements.

- Cold storage; Regards the use of eco-friendly refrigerants in the cold storage rooms and warehouses as well as transportation vehicles in order to provide cold chain services as a crucial part in newly developing markets of foods and pharmaceutical industries. Due to the high energy waste and refrigerant gas leakages, green cold supply chains can be considered as a crucial factor in minimization of environmental problems.

The mentioned indicators, according to experts' opinions and based on the essence of the individual indicators, are decided to classify into three main branches. These main categories of indicators consist of environmental, executive, and strategic indicators, as given by Table 1.

Table 1. Performance indicators.

\begin{tabular}{lcc}
\hline C11 & Organizational environmental management & Competitive pressure \\
C12 & Regulatory pressure & Environmental Indicators \\
C13 & Green design & \\
\hline C21 & Green purchasing & Executive Indicators \\
C22 & Green manufacturing & C2 \\
C23 & Cold storages & \\
C24 & Green transportation & \\
C25 & Operational performance & Strategic Indicators \\
C31 & Economic performance \\
C32 & Environmental performance & \\
C33 & Collaboration between customers and & \\
C34 & suppliers & \\
\hline
\end{tabular}

\section{Research Methodology}

The research method applied in the current study is a survey research. In terms of purpose, this study is applied because it seeks to introduce and apply fuzzy nonlinear mathematical modeling to rank the KPIs of the GSCM in FMCG industries. Solutions are also provided to understand the internal effects of these key performances. The research data were collected through library studies as well as the opinions of active experts in the field under study. The analysis in this study was carried out using questionnaires sent to specialists active in the supply chain of FMCG companies. The main categories and KPIs have been validated using the opinion of the academic professors. In this regard, according to experts' opinion, fuzzy logic is considered as one the best approaches to increase the accuracy of the questionnaires and due to using linguistic variables, the close indicators can be 
distinguished and therefore they can be clearly assessed. The scope of this research is the supply chain of FMCG companies (three pharmaceutical and seven food companies) in Iran. The solution methods are conceptual modeling and fuzzy decision making method in order to investigate the internal effect of indicators. In addition, a group fuzzy preference programming method is applied to understand the importance of indicators and their ranking. In order to converge the answers for the reliability of the questionnaires, we tried to monitor the dispersion of the experts' answers visually. In summary, the evaluation framework of this research consists of four stages as follows:

Step 1: Identifying and evaluating KPI in the green supply chain. In the present study, firstly, by using the literature review of the subject and related articles in the scientific databases of the world, an attempt was made to extract KPIs in the supply chain. Then, employing the views of supply chain experts (in pharmaceutical and food companies), three categories (environmental, executive, and strategic) were selected as key performance categories in the green supply chain and KPI were also identified.

Step 2: Creation of hierarchical structure of decision making. At this stage, hierarchical structure of the decision was determined using objective, criteria, and option levels (Table 1).

Step 3: Determination of internal relationships between indicators. In order to understanding how various indicators affect each other, the fuzzy DEMATEL is used.

Step 4: Calculating weight of indicators using group fuzzy preference programming method. In this study, a fuzzy nonlinear mathematical model will be used to rank the indicators based on pairwise comparisons in the AHP method. Therefore, consensus matrices of fuzzy judgments are formed based on decision makers' views. It is therefore necessary to use fuzzy numbers in explaining people's preferences and opinions.

In the following, we describe the decision making methods used in this study.

\subsection{DEMATEL Method}

DEMATEL method was first created at Science and Human Affairs Program of the Battelle Memorial Institute of Geneva. Since then, it has been widely used in many fields of studies such as evaluating core competencies, decision-making, knowledge management, operations research, and technology research [49]. The most important feature of the DEMATEL method that has been used in MCDM is the possibility of specifying the interrelationships between criteria. The DEMATEL method structure and the relevant calculation procedures can be expressed as follows:

Step 1: Constructing the direct-relation matrix. In order to evaluate the relationship between factors $i$ and $j$, the comparison scale is needed to define as an integer in the range of 0 to 4 in which 0 refers to no influence, 1 refers to low influence, 2 defines the average one, 3 describes the high influence, and 4 represents the very high influence. The integer score $x_{i j}^{i}$ is given by the $k$ th expert where $1 \leq \mathrm{k} \leq \mathrm{H}$ and $H$ refers the number of experts. It shows the degree to which the criterion $i$ affects the criterion $j$. Thus, the $n \times n$ matrix $A$ can be computed by averaging individual expert's scores as written by

$$
\mathrm{a}_{\mathrm{ij}}=\frac{1}{\mathrm{H}} \sum_{\mathrm{k}=1}^{\mathrm{H}} \mathrm{x}_{\mathrm{ij}}^{\mathrm{k}}
$$

Step 2: Normalization of the direct-relation matrix. Based on the direct-relation matrix $A$, the normalized direct-relation matrix $D$ can be calculated as given by

$$
\begin{gathered}
\mathrm{s}=\max \left(\max _{1 \leq \mathrm{i} \leq \mathrm{n}} \sum_{\mathrm{j}=1}^{\mathrm{n}} \mathrm{a}_{\mathrm{ij}}, \max _{1 \leq \mathrm{j} \leq \mathrm{n}} \sum_{\mathrm{i}=1}^{\mathrm{n}} \mathrm{a}_{\mathrm{ij}}\right) \\
D=\frac{A}{\mathrm{~s}}
\end{gathered}
$$


It should be noted that the sum of each rows of matrix $A$ such as $I$ ( $I$ is the identity matrix) indicate the direct effect of whole factor $i$ applied to other factors. Therefore, $\max _{1 \leq i \leq n_{j}=1} \sum_{i j} a_{i j}$ indicates the direct effects of total factor with the most direct effect on other factors and $\max _{1 \leq j \leq n_{i}=1} \sum_{i j} a_{i j}$ shows the most direct effect of total factors received from other factors. Matrix $D$ is obtained by dividing each elements of the matrix $A$ by the s and each element of which is between 0 to 1 .

Step 3: Calculating the total-relation matrix. After obtaining the normalized direct-relation $D$, the total-relation matrix $T$ can be written as

$$
\begin{gathered}
T=D(I-D)^{-1} \\
T=\left[t_{i j}\right]_{n \times n} \quad i, j=1,2,3, \ldots, n
\end{gathered}
$$

Step 4: constructing a cause and effect diagram. Sum of the rows is represented by vector $r$ and sum of columns is denoted by vector $c$. The horizontal axis of vector $(r+c)$, known as 'prominence', describes the importance of the criterion and similarly, the vertical axis $(r-c)$, known as 'relation', divides criteria into a causal group and an effect group. According to the previous statements, a factor can be considered as causal if $(r-c)$ is positive, and the factor is effect when $(r-c)$ is negative. Thus, the cause and effect diagram can be achieved by mapping the dataset of $(r+c, r-c)$. Vectors $r$ and $c$ can be expressed by

$$
\begin{aligned}
& r=\left[\sum_{j=1}^{n} t_{i j}\right]_{n \times 1}=\left[t_{i}\right]_{n \times 1} \\
& c=\left[\sum_{j=1}^{n} t_{i j}\right]_{1 \times n}^{\prime}=\left[t_{j}\right]_{n \times 1}
\end{aligned}
$$

Step 5: Determining the threshold value. In many studies, in order to illustrate the structural relationship between the factors, while maintaining the complexity of the system at the manageable level, it is necessary to determine the threshold value of $\alpha$ in order to filter out only the negligible effects on $T$ matrix. Threshold value $\alpha$ is determined by experts to set up the minimum value of influence level. When the correlative value in the matrix $T$ is smaller than $\alpha$, an influence relationship between two elements will be excluded from the map.

\subsection{Fuzzy Logic}

Most decisions in the real world are inaccurate due to the inaccuracy of understanding the goals, constraints, and possible actions. In light of a fuzzy environment, when a decision is made the results are highly influenced by personal judgments that can be ambiguous and inaccurate. Inaccurate sources can include non-quantifiable information, incomplete information, inaccessible information, and partial ignorance [50]. In order to find out a way to solve the problem of this inaccuracy, fuzzy set theory as a mathematical tool was proposed by Zadeh [51] in 1965 to deal with information uncertainty in decision making process. Since then, this theory has been well developed and has found many successful applications. In fuzzy logic, any number between 0 and 1 represents a part of truth, while in definite sets working with binary logic only two values of 0 and 1 are available.

Thus, fuzzy logic can express inaccurate and imprecise judgments and act mathematically with them [52]. Utilizing the conventional quantification make it difficult to express reasonably the very complicated situations, so using the linguistic variable concept is necessary in such situations. A linguistic variable is a variable whose value has the form of a phrase or sentence in natural language. Linguistic variables are also very functional in dealing with situations described in quantitative terms because these variables' values are linguistic expressions instead of numbers. In practice, linguistic values can be represented using fuzzy numbers, the most common of which are triangular fuzzy 
numbers (TFN). A triangular fuzzy number $\widetilde{A}$ is defined by $[(L, M, U)]$ where $L$ and $U$ are respectively top and bottom boundary of $\widetilde{A}$ as shown in Figure 1. In addition, the fuzzy linguistic scale is shown in Table 2. The fuzzy number $A$ on $R$ is a triangular fuzzy number when the membership function $\mu_{\widetilde{A}}(x): R \rightarrow[0,1]$ is given by

$$
\mu_{\widetilde{A}}(x)=\left\{\begin{array}{cc}
(x-L) /(M-L), & L \leq x \leq M \\
(U-x) /(U-M) & M \leq x \leq U \\
0 & \text { otherwise }
\end{array}\right.
$$

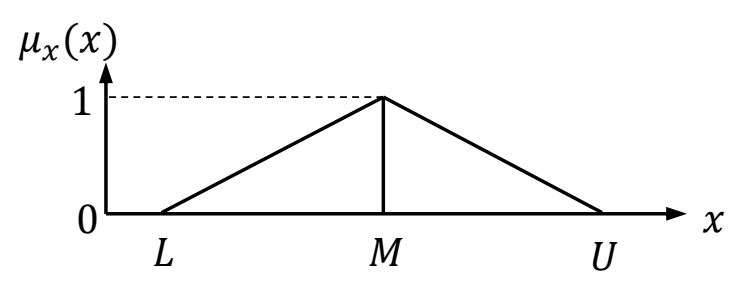

Figure 1. Membership function of triangular fuzzy numbers.

Table 2. Fuzzy linguistic scale.

\begin{tabular}{cc}
\hline Linguistic Terms & Triangular Fuzzy Numbers \\
\hline Very high influence (VH) & $(0.75,1.0,1.0)$ \\
High influence (H) & $(0.5,0.75,1.0)$ \\
Low influence (L) & $(0.25,0.5,0.75)$ \\
Very low influence (VL) & $(0,0.25,0.5)$ \\
No influence (No) & $(0,0,0.25)$ \\
\hline
\end{tabular}

\subsection{Application of Fuzzy Logic in DEMATEL Method}

One of the issues with using the DEMATEL method is to obtain the direct effect size between the two factors. The size of these concessions is always obtained by using expert surveys; but in many cases people's judgment in decision making is unclear and cannot be measured using precise numerical values; therefore, it is necessary to use fuzzy logic in dealing with issues that are ambiguous and inaccurate. To employ fuzzy logic in DEMATEL method, experts should first be asked to respond on the basis of defined linguistic variables (presented in Table 2) as pairwise comparisons to determine the effect of factors on each other. To overcome the ambiguities of human evaluations, the linguistic variable of 'influence' is used through the five expressions of very high, high, low, very low, and none, described as positive triangular fuzzy numbers $\left(l_{i j}, m_{i j}, r_{i j}\right)$. After obtaining expert opinions, we calculate the fuzzy mean matrix using fuzzy averaging. Then using the existing equations to convert the fuzzy values into the non-fuzzy numbers, matrix of the final mean values is calculated.

Therefore, if we have $p$ responders, we will have fuzzy matrices as much as respondents. Now we calculate the fuzzy mean matrix, so we will have

$$
\widetilde{z}=\frac{\left(\widetilde{z}^{1}+\widetilde{z}^{2}+\ldots+\widetilde{z}^{p}\right)}{p}
$$

The $\widetilde{z}$ matrix is called the fuzzy primary relation matrix or the intermediate fuzzy matrix, which is represented as

$$
\widetilde{z}=\left[\begin{array}{cccc}
0 & \widetilde{z}_{12} & \cdots & \widetilde{z}_{1 n} \\
\widetilde{z}_{21} & 0 & \cdots & \widetilde{z}_{1 n} \\
\vdots & \vdots & \ddots & \vdots \\
\widetilde{z}_{n 2} & \widetilde{z}_{n 2} & \cdots & 0
\end{array}\right]
$$


Now by using a deffuzication method, initial direct-relation matrix can be achieved. In order to transform TFN numbers to crisp values, we use converting fuzzy data into crisp scores (CFCS) defuzzication method [52]. In this method the final value is defined as average weight in accordance with the membership function. If $\left(l_{i j}, m_{i j}, r_{i j}\right)$ indicates the effect of criterion $i$ on the criterion $j$ in the fuzzy matrix of the direct relation, then the CFCS method can be summarized in the following steps:

The first step is normalization

$$
\begin{aligned}
x l_{i j} & =\left(l_{i j}-\min l_{i j}\right) / \Delta_{\min }^{\max } \\
x m_{i j} & =\left(m_{i j}-\min l_{i j}\right) / \Delta_{\min }^{\max } \\
x r_{i j} & =\left(r_{i j}-\min l_{i j}\right) / \Delta_{\min }^{\max }
\end{aligned}
$$

where

$$
\Delta_{\min }^{\max }=\max r_{i j}-\min l_{i j}
$$

In the second step, we calculate the values on the right and left

$$
\begin{aligned}
& x l s_{i j}=x m_{i j} /\left(1+x m_{i j}-x l_{i j}\right) \\
& x r s_{i j}=x r_{i j} /\left(1+x r_{i j}-x m_{i j}\right)
\end{aligned}
$$

In the third step, we calculate the total normalized definite value

$$
x_{i j}=\left[x l s_{i j}\left(1-x l s_{i j}\right)+x r s_{i j}\right] /\left[1-x l s_{i j}+x r s_{i j}\right\}
$$

In the last step we calculate the final definitive value

$$
z_{i j}=\min l_{i j}+x_{i j} \Delta_{\min }^{\max }
$$

\subsection{Non-Linear Fuzzy Prioritization}

In this section, a non-linear method for KPI prioritization is proposed in order to find directly crisp values of priorities from a set of comparison judgments, represented as triangular fuzzy numbers (as shown in Figure 1) [53]. We want to find a crisp priority vector so that the ratios almost satisfy the fuzzy initial judgments of $\widetilde{a}_{i j}=\left(l_{i j}, m_{i j}, u_{i j}\right)$ or

$$
l_{i j} \simeq \frac{w_{i}}{w_{j}} \widetilde{\leq} u_{i j}
$$

where the symbol $\widetilde{\leq}$ refers to the statement of fuzzy less or equal to.

In order to handle the above inequalities easily, they can be defined as a set of single-side fuzzy constraints as follows

$$
\begin{aligned}
& w_{i}-w_{j} u_{i j} \leq 0 \\
& -w_{i}+w_{j} l_{i j} \leq 0
\end{aligned}
$$

The set of $2 m$ fuzzy constraints can be written in a matrix form as

$$
R w \widetilde{\leq} 0
$$

in which the matrix $R \in \mathfrak{R}^{2 m \times n}$. 
Then for each fuzzy judgment, a membership function can be constructed that is linear with respect to $w_{i} / w_{j}$ and can be given by

$$
\mu_{i j}\left(\frac{w_{i}}{w_{j}}\right)= \begin{cases}\frac{\left(\frac{w_{i}}{w_{j}}-l_{i j}\right)}{m_{i j}-l_{i j}} & \frac{w_{i}}{w_{j}} \leq m_{i j} \\ u_{i j}-\left(\frac{w_{i}}{w_{j}}\right) & \frac{w_{i}}{u_{j}} \leq m_{i j}\end{cases}
$$

Function (22) is linearly increasing over the interval $\left(-\infty, m_{i j}\right)$ and linearly decreasing over the interval $\left(m_{i j}, \infty\right)$. It takes negative values when $w_{i} / w_{j}<l_{i j}$ or $w_{i} / w_{j}>u_{i j}$ and has a maximum value $\mu_{i j}=1$ at $w_{i} / w_{j}=m_{i j}$. Over the range $\left(l_{i j}, u_{i j}\right)$ the membership function (22) coincides with the fuzzy triangular judgment $\widetilde{a}_{i j}=\left(l_{i j}, m_{i j}, u_{i j}\right)$.

Function (22) is non-linear with respect to the decision variables, but provides a fuzzy feasible area, linear in these ratios. We can define a fuzzy feasible area on $(n-1)$-dimensional simplex (23) as the intersection of all membership functions (22) and apply a max-min-approach for finding the maximizing solution.

$$
Q^{n-1}=\left\{\left(w_{1}, \ldots, w_{n}\right) \mid w_{i}>0, \quad w_{1}+\ldots+w_{n}=1\right\}
$$

This leads to the following non-linear optimization problem

$$
\begin{aligned}
& \max \lambda \\
& \text { s.t: }\left(m_{i j}-l_{i j}\right) \lambda w_{j}-w_{i}+l_{i j} w_{j} \leq 0 \\
& \left(u_{i j}-m_{i j}\right) \lambda w_{j}+w_{i}-u_{i j} w_{j} \leq 0 \\
& \sum_{k=1}^{n} w_{k}=1 \\
& w_{k}>0 \quad, k=1,2, \ldots, n ; \quad i=1,2, \ldots, n-1 ; j=2,3, \ldots, n \text { ， } \\
& j>i
\end{aligned}
$$

The solution of the above non-linear problem (24) needs some appropriate numerical method for non-linear optimization to be employed.

To use the function (24), the pairwise comparisons matrix will be obtained by using AHP method [54] and by integrating expert opinions. Fuzzy linguistic scales will be used to obtain expert opinions. These linguistic scales for the matrix of pairwise comparisons and their fuzzy equations are shown in Table 3. The optimum positive value of the indicator in this function (24) reveals that all weight ratios are completely true to the original judgment. However, if the indicator is negative, it can be seen that fuzzy judgments were strongly incompatible.

Table 3. Linguistic scales for pairwise comparisons and their fuzzy equivalents.

\begin{tabular}{cc}
\hline Triangular Fuzzy Scales & Linguistic Values for Pairwise Comparisons \\
\hline Verylow & $(1,2,3)$ \\
Low & $(2,3,4)$ \\
Medium & $(3,4,5)$ \\
High & $(4,5,6)$ \\
Very high & $(5,6,7)$ \\
\hline
\end{tabular}

\section{Research Findings}

\subsection{Internal Relationship and Severity of Impact between Performance Indicators}

In this study, in order to investigate the internal effects of performance indicators, fuzzy DEMATEL method was employed. To this end, 50 questionnaires were sent to specialists working in the FMCG 
industry, among which 40 questionnaires were completed and came to us. To examine effective internal relationships, experts were asked to state their theories about the impact of each performance indicator on the other ones, based on linguistic options and triangular fuzzy positive numbers (as shown by Table 2) through paired comparisons between the factors obtained from the research. The fuzzy direct relation matrix was formed for the performance indicators as presented in Tables 4 and 5.

Table 4. Fuzzy direct relation matrix between the main categories.

\begin{tabular}{cccccccccc}
\hline & & $\mathbf{C 1}$ & & & $\mathbf{C} 2$ & & \multicolumn{3}{c}{ C3 } \\
\cline { 2 - 10 } & $\mathbf{L}$ & $\mathbf{M}$ & $\mathbf{U}$ & $\mathbf{L}$ & $\mathbf{M}$ & $\mathbf{U}$ & $\mathbf{L}$ & $\mathbf{M}$ & $\mathbf{U}$ \\
\hline C1 & 0 & 0 & 0 & 0.8 & 0.6 & 0.4 & 0.85 & 0.75 & 0.25 \\
$\mathbf{C 2}$ & 0.8 & 0.75 & 0.35 & 0 & 0 & 0 & 0.85 & 0.75 & 0.55 \\
C3 & 0.5 & 0.2 & 0.15 & 0.5 & 0.25 & 0 & 0 & 0 & 0 \\
\hline
\end{tabular}

Table 5. Fuzzy direct relationship matrix between performance indicators.

\begin{tabular}{|c|c|c|c|c|c|c|c|c|c|c|c|c|c|}
\hline & \multicolumn{3}{|c|}{ C11 } & \multicolumn{3}{|c|}{ C12 } & \multirow{2}{*}{$\frac{C \ldots}{\ldots}$} & \multicolumn{3}{|c|}{ C33 } & \multicolumn{3}{|c|}{ C34 } \\
\hline & L & $\mathbf{M}$ & $\mathbf{U}$ & L & $\mathbf{M}$ & $\mathbf{U}$ & & L & $\mathbf{M}$ & $\mathbf{U}$ & L & $\mathbf{M}$ & $\mathbf{U}$ \\
\hline C11 & 0 & 0 & 0 & 0.8 & 0.45 & 0.3 & $\ldots$ & 0.65 & 0.35 & 0.1 & 0.95 & 0.45 & 0.15 \\
\hline C12 & 0.9 & 0.95 & 0.45 & 0 & 0 & 0 & $\ldots$ & 0.85 & 0.6 & 0.35 & 0.7 & 0.35 & 0.25 \\
\hline$\ldots$ & $\ldots$ & & $\ldots$ & $\ldots$ & $\cdots$ & $\ldots$ & $\ldots$ & & $\ldots$ & $\cdots$ & $\ldots$ & $\ldots$ & \\
\hline C 33 & 0.75 & 0.85 & 0.45 & 0.9 & 085 & 0.3 & $\ldots$ & 0 & 0 & 0 & 0.9 & 0.85 & 0.50 \\
\hline C34 & 0.7 & 0.65 & 0.35 & 0.9 & 0.6 & 0.45 & $\ldots$ & 0.2 & 0.85 & 0.45 & 0 & 0 & 0 \\
\hline
\end{tabular}

In Tables 6 and 7 , the general fuzzy relationship matrix for the main categories and performance indicators are demonstrated, respectively.

Table 6. Total fuzzy relation matrix for the main categories.

\begin{tabular}{cccccccccc}
\hline & & C1 & & & C2 & & \multicolumn{3}{c}{ C3 } \\
\cline { 2 - 10 } & $\mathbf{L}$ & $\mathbf{M}$ & $\mathbf{U}$ & $\mathbf{L}$ & $\mathbf{M}$ & $\mathbf{U}$ & $\mathbf{L}$ & $\mathbf{M}$ & $\mathbf{U}$ \\
\hline C1 & 0.9 & 0.5 & 0.13 & 1.2 & 0.44 & 0.23 & 1.2 & 0.55 & 0.34 \\
C2 & 1.35 & 0.6 & 0.43 & 1.1 & 0.45 & 0.1 & 1.3 & 0.77 & 0.45 \\
C3 & 1.13 & 0.24 & 0.11 & 0.45 & 0.23 & 0.04 & 0.65 & 0.22 & 0.07 \\
\hline
\end{tabular}

Table 7. Total fuzzy relation matrix for performance indicators.

\begin{tabular}{|c|c|c|c|c|c|c|c|c|c|c|c|c|c|}
\hline & \multicolumn{3}{|c|}{ C11 } & \multicolumn{3}{|c|}{ C12 } & \multirow{2}{*}{$\frac{C \ldots}{\ldots}$} & \multicolumn{3}{|c|}{ C33 } & \multicolumn{3}{|c|}{ C34 } \\
\hline & $\mathbf{L}$ & $\mathbf{M}$ & $\mathbf{U}$ & $\mathbf{L}$ & $\mathbf{M}$ & $\mathbf{U}$ & & $\mathbf{L}$ & $\mathbf{M}$ & $\mathbf{U}$ & $\mathbf{L}$ & $\mathbf{M}$ & $\mathbf{U}$ \\
\hline C11 & 0.11 & 0.1 & 0.06 & 0.23 & 0.2 & 0.07 & $\ldots$ & 0.2 & 0.11 & 0.09 & 0.21 & 0.11 & 0.08 \\
\hline $\mathrm{C} 12$ & 0.25 & 0.13 & 0.05 & 0.2 & 0.1 & 0.04 & $\ldots$ & 0.2 & 0.13 & 0.07 & 0.22 & 0.13 & 0.07 \\
\hline C & & & & & $\ldots$ & & & & & $\ldots$ & $\ldots$ & $\ldots$ & $\ldots$ \\
\hline$\ldots$ & 0.25 & $\cdots$ & 0.1 & 02 & 0.14 & 012 & $\cdots$ & 0.15 & 0.12 & 0.04 & 018 & 0.2 & 0.07 \\
\hline C34 & 0.26 & 0.16 & 0.1 & 0.24 & 0.13 & 0.1 & $\ldots$ & 0.2 & 0.18 & 0.12 & 0.17 & 0.2 & 0.07 \\
\hline
\end{tabular}

To compile the relationship map, the sum of the elements of the columns and rows of total matrix for the main categories as well as the KPIs were calculated. These values are nominated as effective $(R)$ and Influential $(D)$ vectors. The results are shown in Table 8. 
Table 8. Results of the calculations of the effect of performance indicators

\begin{tabular}{ccccc}
\hline KPI & $\mathbf{D}$ & $\mathbf{R}$ & $\mathbf{D}+\mathbf{R}$ & $\mathbf{D}-\mathbf{R}$ \\
\hline Environmental Indicators & 3.651 & 2.234 & 5.885 & 1.417 \\
Organizational environmental management & 0.857 & 0.611 & 1.468 & 0.246 \\
Competitive pressure & 0.872 & 0.66 & 1.532 & 0.212 \\
Regulatory pressure & 0.245 & 0.235 & 0.48 & 0.01 \\
\hline Executive Indicators & 3.547 & 2.783 & 6.33 & 0.764 \\
Green design & 0.376 & 0.42 & 0.796 & -0.044 \\
Green purchasing & 0.387 & 0.444 & 0.831 & -0.057 \\
Green manufacturing & 0.387 & 0.413 & 0.8 & -0.026 \\
Cold storages & 0.523 & 0.397 & 0.92 & 0.126 \\
Green transportation & 0.293 & 0.28 & 0.573 & 0.013 \\
\hline Strategic Indicators & 3.287 & 2.98 & 6.267 & 0.307 \\
Operational performance & 0.217 & 0.234 & 0.451 & -0.017 \\
Economic performance & 0.225 & 0.235 & 0.46 & -0.01 \\
Environmental performance & 0.251 & 0.254 & 0.505 & -0.003 \\
Collaboration between customers and suppliers & 0.341 & 0.333 & 0.674 & 0.008 \\
\hline
\end{tabular}

Then, based on Table 8, the network relations map of the performance indicators will be obtained. This is illustrated in Figure 2. As can be seen, Figure 2a demonstrates the internal effects of main category of performance indicators. Additionally, Figure $2 b-d$ describes the internal effects of KPIs in respectively environmental, executive and strategic categories. As can be seen in Figure 2, environmental indicators have the greatest effect on the strategic and executive indicators. At the same time, the most influential indicators among the presented categories can be clearly seen in this figure.

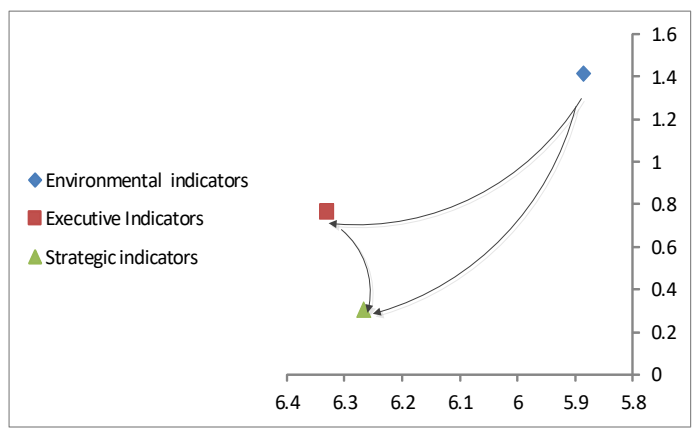

(a)

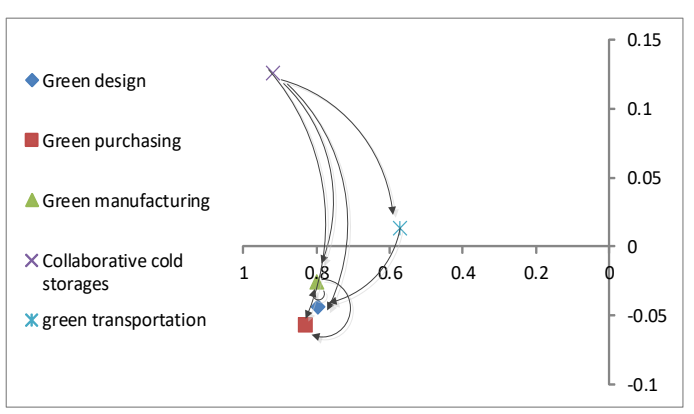

(c)

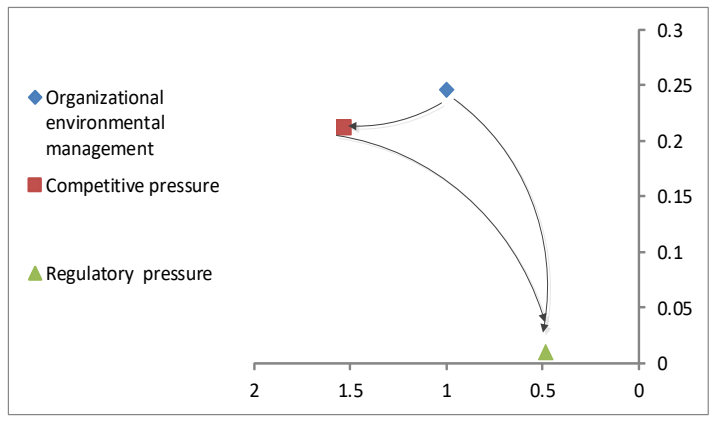

(b)

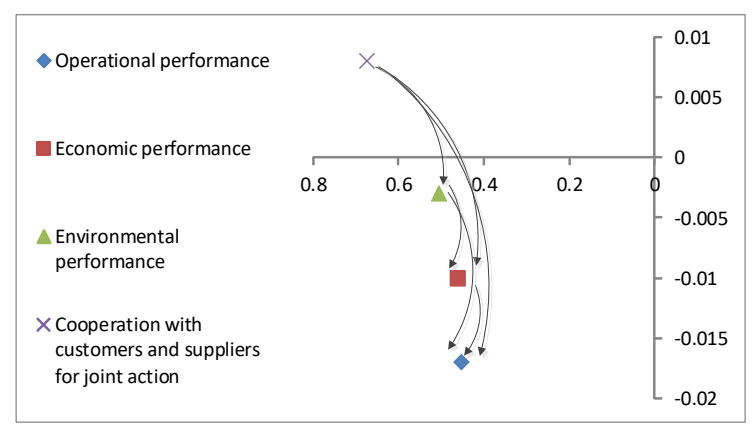

(d)

Figure 2. The network of influential relationships: (a) demonstrates the internal effects of main category of performance indicators. (b-d) describes the internal effects of KPIs in respectively environmental, executive, and strategic categories. 


\subsection{Evaluating and Ranking Performance Indicators Using Non-Linear Fuzzy Prioritization Method}

In this study, a non-linear fuzzy prioritization method based on AHP was used to evaluate and rank the indicators obtained by using field and study methods. For this purpose, 35 specialists including 25 experts of the food industry and 10 specialists in the pharmaceutical industry, among the top supply chain managers and senior supervisors of supply chain of the FMCG industries with more than 10 years' work experience were selected and questionnaires were sent to them. Then, experts were asked to use paired comparisons using linguistic criteria (Table 3) to analyze KPIs in green supply chain and we received the answers of all experts. Therefore, evaluation and ranking of green supply chain's KPI in FMCG companies are divided into two parts.

(1) Fuzzy pairwise comparison matrix determination based on integration of expert opinions that is expressed according to linguistic criteria presented in Table 3.

(2) Solving the proposed nonlinear mathematical model (function 24) using pairwise comparisons matrices and finally gaining the weight of KPI.

The pairwise comparisons matrix for green supply chain KPI, based on the integration of expert opinion, is shown in Tables 9-12. We will use these paired comparisons for our calculations in the mathematical model.

Table 9. Paired comparison matrix of KPIs in the FMCG industry green supply chain, based on integration of experts.

\begin{tabular}{cccccccccc}
\hline & \multicolumn{3}{c}{ Environmental } & \multicolumn{3}{c}{ Executive } & \multicolumn{3}{c}{ Strategic } \\
\cline { 2 - 9 } & \multicolumn{3}{c}{ W1 } & \multicolumn{3}{c}{ W2 } & \multicolumn{3}{c}{ W3 } \\
\hline W1 & - & - & - & - & - & - & - & - & - \\
W2 & 2.7 & 2.9 & 6.7 & - & - & - & - & - & - \\
W3 & 2.5 & 2.6 & 3.2 & 1.1 & 1.3 & 3.1 & - & - & - \\
\hline
\end{tabular}

Table 10. Paired comparison matrix of KPIs in the FMCG industry green supply chain, based on integration of experts in environmental section.

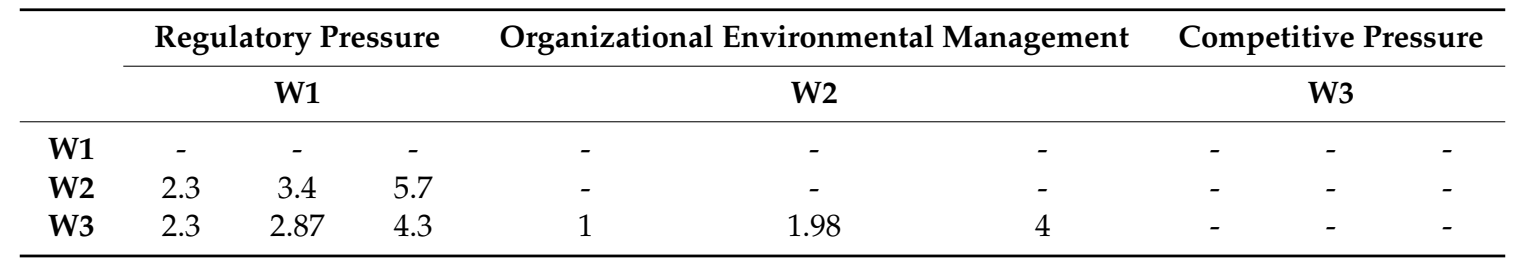

Table 11. Paired comparison matrix of KPIs in the FMCG industry green supply chain, based on integration of experts in executive section.

\begin{tabular}{|c|c|c|c|c|c|c|c|c|c|c|c|c|c|c|c|}
\hline \multirow[b]{3}{*}{ W1 } & \multirow{2}{*}{\multicolumn{3}{|c|}{$\begin{array}{c}\begin{array}{c}\text { Green } \\
\text { Purchasing }\end{array} \\
\text { W1 }\end{array}$}} & \multicolumn{3}{|c|}{ Green Design } & \multicolumn{3}{|c|}{ Cold Storages } & \multicolumn{3}{|c|}{$\begin{array}{c}\text { Green } \\
\text { Manufacturing }\end{array}$} & \multicolumn{3}{|c|}{$\begin{array}{c}\text { Green } \\
\text { Transportation }\end{array}$} \\
\hline & & & & & W2 & & & W3 & & & W4 & & & W5 & \\
\hline & - & - & - & - & - & - & - & - & - & - & - & - & - & - & - \\
\hline W2 & 1.12 & 1.56 & 2 & - & - & - & - & - & - & - & - & - & - & - & - \\
\hline W3 & 1.54 & 2.65 & 4 & 1.64 & 2.69 & 7.3 & - & - & - & - & - & - & - & - & - \\
\hline W4 & 1.16 & 1.76 & 2.7 & 1 & 1.3 & 5.49 & 0.5 & 1 & 1 & - & - & - & - & - & - \\
\hline W5 & 1.13 & 1.29 & 2.51 & 1.21 & 1.25 & 4 & 0.8 & 1 & 1.1 & 1.2 & 1.1 & 1.6 & & - & - \\
\hline
\end{tabular}


Table 12. Paired comparison matrix of KPIs in the FMCG industry green supply chain, based on integration of experts in strategic section.

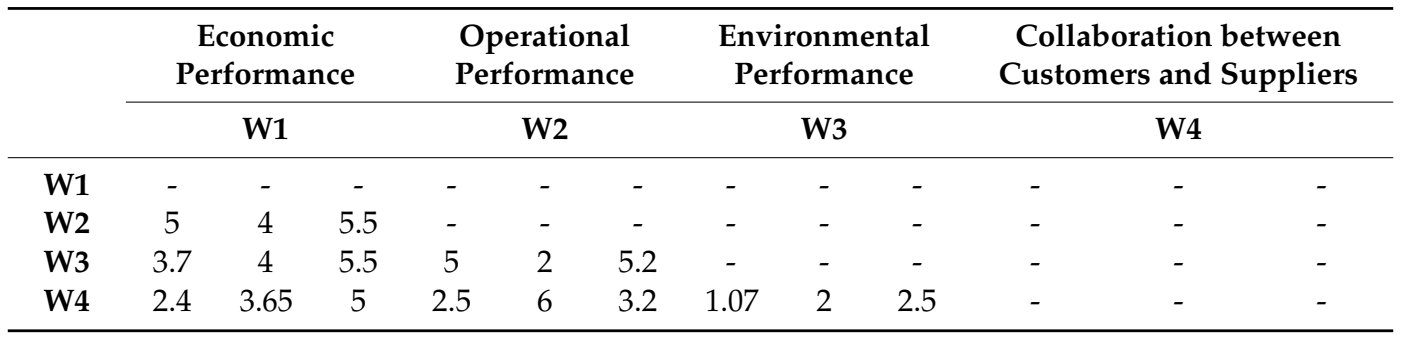

After performing pairwise comparisons of expert opinions on different sections, we will use the data from these matrices in mathematical modeling to ranking. We put fuzzy values in the mathematical model. Since the model is nonlinear, we use GAMS software to solve the model. Thus, the weight and rank of the criteria and sub-criteria will be obtained, which is visible in Tables 13-16.

Table 13. Weight and ranking of KPIs in main category (taken from fuzzy nonlinear model).

\begin{tabular}{cccc}
\hline KPI & Code & Weight & Rank \\
\hline Environmental & W1 & 0.4183452 & 1 \\
Executive & W2 & 0.2959360 & 2 \\
Strategic & W3 & 0.2857188 & 3 \\
\hline
\end{tabular}

Table 14. Weight and ranking of KPIs in environmental indicators category (taken from fuzzy nonlinear model).

\begin{tabular}{cccc}
\hline KPI & Code & Weight & Rank \\
\hline Regulatory pressure & W1 & 0.2583772 & 2 \\
Organizational environmental management & W2 & 0.5032456 & 1 \\
Competitive pressure & W3 & 0.2383772 & 3 \\
\hline
\end{tabular}

Table 15. Weight and ranking of KPIs in executive indicators category (taken from fuzzy nonlinear model).

\begin{tabular}{cccc}
\hline KPI & Code & Weight & Rank \\
\hline Green purchasing & W1 & 0.1243567 & 5 \\
Green design & W2 & 0.1434582 & 4 \\
Cold storages & W3 & 0.3193412 & 1 \\
Green manufacturing & W4 & 0.1900213 & 3 \\
Green transportation & W5 & 0.2228236 & 2 \\
\hline
\end{tabular}

Table 16. Weight and ranking of KPIs in strategic indicators category (taken from fuzzy nonlinear model).

\begin{tabular}{cccc}
\hline KPI & Code & Weight & Rank \\
\hline Economic performance & W1 & 0.2911781 & 2 \\
Operational performance & W2 & 0.2151470 & 3 \\
Environmental performance & W3 & 0.3213857 & 1 \\
Collaboration between customers and suppliers & W4 & 0.1722892 & 4 \\
\hline
\end{tabular}

After calculating the weights of each KPI, we can normalize the weights using the information in Tables 13-16. The normalized weight for the green supply chain's KPI is shown in Table 17. The normalized weight represents the overall rank of the KPI. In addition, Figure 3 shows that the organizational environmental management and regulatory pressure are more important than the 
other indicators because they have a higher weight than others. Therefore, GSCM can be successfully implemented when the top level management considers green practices as their company policies in view of the systems to track environmental laws as well as documented procedure to implement corrective action plan. Regulatory pressure gets the next highest weightage which obviously shows that the government, customers, and stockholders can play a significant role in implementation of GSCM. Furthermore, the third place represents effect of competitor's green strategies to successfully implement GSCM. Cold storage achieved the fourth weightage, which shows that green cold supply chains are a major concern in minimization of environmental problems. Other KPIs occupied the resting ranks, as presented by Table 17 and Figure 3.

Table 17. Normalized weight and ranking of KPIs in the green supply chain (FMCG industries).

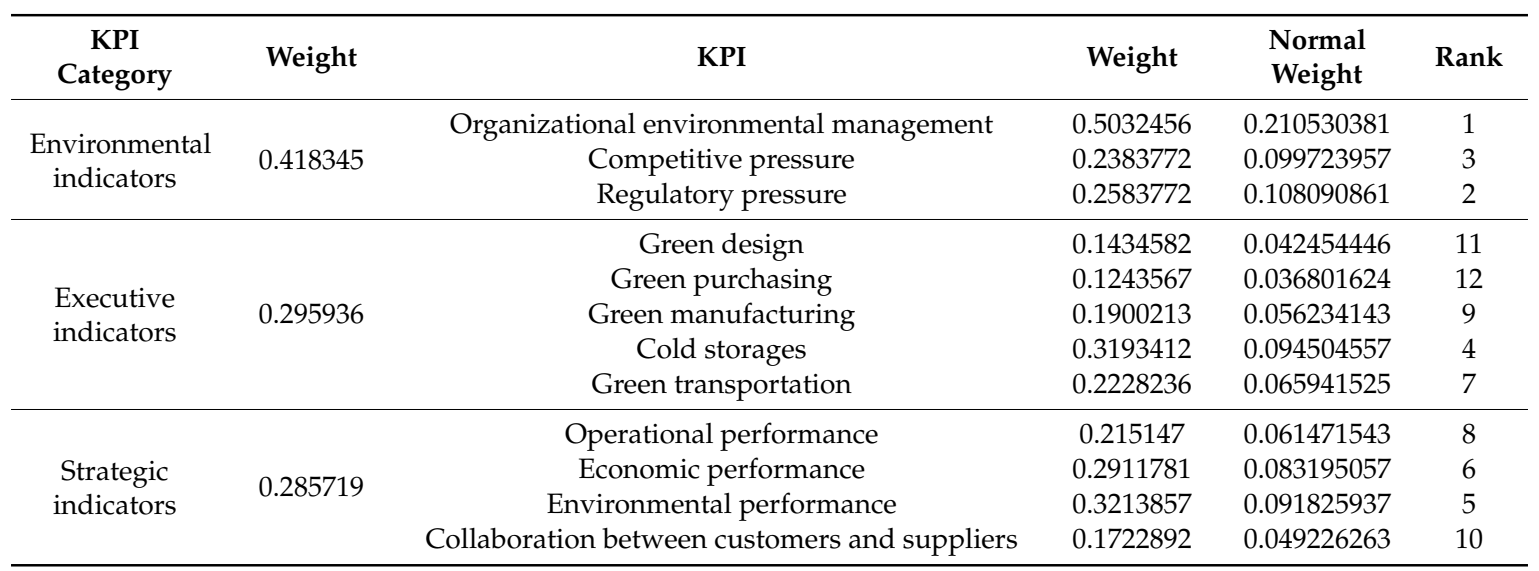

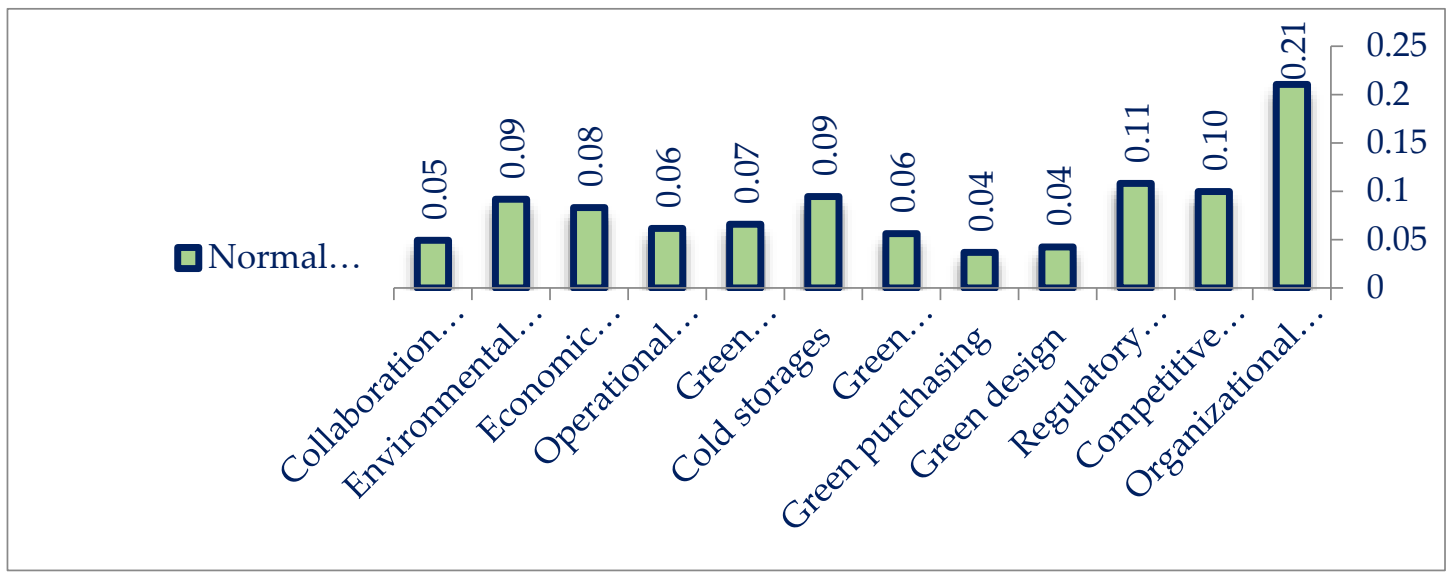

Figure 3. Importance of KPIs of the green supply chain in the FMCG industry.

\section{Conclusions}

Recently, many industries are moving towards being greener in their supply chain processes due to customers' needs as well as the scarce resources and policies of governments for different industries. In other world, GSCM accomplishment has become a significant issue for industries in the present competitive market that may be successfully implemented in any company through which every employee works such as a link of a chain. Therefore, reviewing the performance and explaining KPIs for the green supply chain play a great important role in many industries. Prioritizing these functions can lead to effective management of green supply chain processes in the organization. The FMCG industries are highly regarded due to the type of production of their products that are very fast consuming (the food and pharmaceutical industries fall within this range) and given the specific distribution dimensions and delivery schedules. Therefore, due to the importance of the subject, this study has attempted to identify KPIs in the FMCG green supply chain based on the literature review 
as well as the views of experts in the FMCG industry. In accordance with experts' opinions and based on the essence of the individual indicators, they were classified into three main categories, including 12 KIPs. Subsequently, by using fuzzy decision making approach and by distributing the questionnaire among the supply chain experts in the FMCG industry, the relationships of internal effects on the indicators were determined. Then a fuzzy nonlinear mathematical model by innovatively applying the AHP method was used to evaluate and prioritize KPIs. The results indicated that organizational environmental management is the highest priority among the KPIs in the green supply chain of FMCG industries, limited to food and pharmaceutical industries. In addition, it was found that indicators of regulatory pressures as well as competitive pressures are in the next rank and all of the first three ranks occupied by the main category of environmental indicators. Moreover, it was revealed that cold storage as an executive indicator, and afterwards the environmental performance as a strategic indicator acquired the next ranks. Therefore, it seems that FMCG industry executives and decision makers need to give more weight to these indicators to improve organizational performance in the green supply chain.

Author Contributions: Conceptualization, H.N. and E.N.; methodology, H.N.; software, H.N. and E.N.; validation, M.F. and F.H.; formal analysis, H.N.; investigation, H.N., E.N., M.F. and F.H.; resources, M.F. and F.H.; data curation, H.N.; writing—original draft preparation, H.N.; writing—review and editing, E.N.; supervision, E.N., M.F. and F.H.; project administration, E.N., M.F. and F.H.

Funding: This research received no external funding.

Conflicts of Interest: The authors declare no conflicts of interest.

\section{References}

1. Mangla, S.K.; Kumar, P.; Barua, M.K. Prioritizing the responses to manage risks in green supply chain: An indian plastic manufacturing prespective. Sustain. Prod. Consum. 2015, 1, 67-86. [CrossRef]

2. Wu, H.H.; Chang, S.Y. Case study of using dematel method to identify critical factors in green supply chain management. Appl. Math. Comput. 2015, 256, 394-403. [CrossRef]

3. Cousins, P.; Lawson, B.; Petersen, K.; Fugate, B. Investigating green supply chain management practices and performance. Int. J. Oper. Prod. Manag. 2019, 39, 767-786. [CrossRef]

4. Seman, N.A.A.; Govindan, K.; Mardani, A.; Zakuan, N.; Saman, M.Z.M.; Hooker, R.E.; Ozkul, S. The mediating effect of green innovation on the relationship between green supply chain management and environmental performance. J. Clean. Prod. 2019, 229, 115-127. [CrossRef]

5. Arlbjørn, J.S. Supply Chain Management; Academica: London, UK, 2010.

6. Kotler, P.; Armstrong, G. Principles of Marketing, 13th ed.; Pearson Prentice Hall: Upper Saddle River, NJ, USA, 2011.

7. Menidjel, C.; Benhabib, A.; Bilgihan, A. Examining the moderating role of personality traits in the relationship between brand trust and brand loyalty. J. Prod. Brand Manag. 2017, 6, 631-649. [CrossRef]

8. Aljunaidi, A.; Ankrah, S. The Application of Lean Principles in the Fast Moving Consumer Goods (FMCG). J. Oper. Supply Chain Manag. 2014, 7, 1-25. [CrossRef]

9. Colicchia, C.; Creazza, A.; Dallari, F. Lean and green supply chain management through intermodal transport: Insights from the fast moving consumer goods industry. Prod. Plan. Control 2017, 28, 321-334. [CrossRef]

10. Bourlakis, M.A.; Weightman, P.W. Food Supply Chain Management, 1st ed.; Ames, I.A., Ed.; Blackwell Publishing: Hoboken, NJ, USA, 2004.

11. Fernie, J.; Sparks, L. Logistics and Retail Management: Emerging Issues and New Challenges in the Retail Supply Chain; Kogan Page: London, UK, 2014.

12. Monios, J. Integrating Intermodal Transport with Logistics: A Case Study of the UK Retail Sector. Transp. Plan. Technol. 2015, 38, 347-374. [CrossRef]

13. Green, S. Durable vs. Non-Durable Goods: What's the Difference? 2016. Available online: https://rjofutures. rjobrien.com/market-news/2016/05/05/durable-vs-non-durable-goods-whats-the-difference (accessed on 25 June 2019).

14. Malhotra, S. A study on marketing fast moving consumer goods (FMCG). Int. J. Innov. Res. Dev. 2014, 1, 1-3. 
15. Anselmsson, J.; Burt, S.; Tunca, B. An integrated retailer image and brand equity framework: Re-examining, extending, and restructuring retailer brand equity. J. Retail. Consum. Serv. 2017, 38, 194-203. [CrossRef]

16. Council, F.L. La Sostenibilità nei Trasporti e nella Logistica: Quaderno. 2016. Available online: http: //www.freightleaders.org/i-quaderni/ (accessed on 25 June 2019).

17. Singh, R.K.; Acharya, P. Identification and Evaluation of Supply Chain Flexibilities in Indian FMCG Sector Using DEMATEL. Glob. J. Flex. Syst. Manag. 2014, 15, 91-100. [CrossRef]

18. Craggs, J.A. Maturity Assessment of Green Supply Chain Management in the South African FMCG Industry; University of Pretoria: Pretoria, South Africa, 2012.

19. Schoeman, C.; Sanchez, V.R. Green Supply Chain Overview and A South African Case Study. In Proceedings of the 28th Southern African Transport Conference, Pretoria, South Africa, 8-11 July 2009.

20. Li, X.; Wang, Q. Coordination mechanism of supply chain systems. Eur. J. Oper. Res. 2007, 179, 1 e6. [CrossRef]

21. Gilber, S. Greening Supply Chain: Enhancing Competitiveness through Green Productivity; Asian Productivity Organization: Tapei, Taiwan, 2001.

22. Rao, P.; Holt, D. Do green supply chains lead to competitiveness and economic performance? Int. J. Oper. Prod. Manag. 2005, 25, 898. [CrossRef]

23. Acevedo, M.F. Interdisciplinary progress in food production, food security and environment. Environ. Conserv. 2011, 38, 151-171. [CrossRef]

24. Dharni, K.; Sharma, R.K. Supply chain management in food processing sector: Experience from India. Int. J. Logist. Syst. Manag. 2015, 21, 115-132. [CrossRef]

25. Gardas, B.B.; Raut, R.D.; Narkhede, B. Modeling causal factors of post-harvesting losses in vegetable and fruit supply chain: An Indian perspective. Renew. Sustain. Energy Rev. 2017, 80, 1355-1371. [CrossRef]

26. Liang, L.; Feng, F.; Cook, W.D.; Zhu, J.D. A models for supply chain efficiency evaluation. Ann. Oper. Res. 2006, 145, 35-49. [CrossRef]

27. Akkerman, R.; Farahani, P.; Grunow, M. Quality, safety and sustainability in food distribution: A review of quantitative operations management approaches and challenges. Oper. Res. Spektrum 2010, 32, 863-904. [CrossRef]

28. Bhat, V. Green Marketing Begins with Green Design. J. Bus. Ind. Mark. 1993, 8, 26-31. [CrossRef]

29. Wiley, J.A.; Benefield, J.D.; Johnson, K.H. Green Design and the Market for Commercial Office Space. J. Real Estate Financ. Econ. 2010, 41, 228-243. [CrossRef]

30. Siyavooshi, M.; Foroozanfar, A.; Sharifi, Y. Effect of Islamic values on green purchasing behavior. J. Islam. Mark. 2019, 10, 125-137. [CrossRef]

31. Chekima, B.; Azizi, K.W.S.; AisatIgau, O.; Chekima, S. Examining green consumerism motivational drivers: Does premium price and demographics matter to green purchasing? J. Clean. Prod. 2016, 112, 3436-3450. [CrossRef]

32. Foo, M.; Kanapathy, K.; Zailani, S.; Shaharudin, M.R. Green purchasing capabilities, practices and institutional pressure. Manag. Environ. Qual. 2019, 30,1171-1189. [CrossRef]

33. Rusinko, C. Green Manufacturing: An Evaluation of Environmentally Sustainable Manufacturing Practices and Their Impact on Competitive Outcomes. IEEE Trans. Eng. Manag. 2007, 54, 445-454. [CrossRef]

34. Dornfeld, D.A. Green Manufacturing: Fundamentals and Applications; Springer Science \& Business Media: New York, NY, USA, 2013.

35. Govindan, K.; Diabat, A.; Shankar, K.M. Analyzing the drivers of green manufacturing with fuzzy approach. J. Clean. Prod. 2015, 96, 182-193. [CrossRef]

36. Panday, A.; Bansal, B.O. Green transportation: Need, technology and challenges. Int. J. Glob. Energy 2015, 37, 304-318. [CrossRef]

37. Lin, R.J. Using fuzzy DEMATEL to evaluate the green supply chain management practices. J. Clean. Prod. 2013, 40, 32-39. [CrossRef]

38. von Malmborg, F.B. Environmental management systems, communicative action and organizational learning. Bus. Strategy Dev. 2002, 11, 312-313.

39. Carpitella, S.; Carpitella, F.; Certa, A.; Benítez, J.; Izquierdo, J. Managing Human Factors to Reduce Organisational Risk in Industry. Math. Comput. Appl. 2018, 23, 67. [CrossRef] 
40. Zhu, Q.; Sarkis, J. Relationship between operational practices and performances among early adopters of Green Supply Chain Management practices in Chinese manufacturing enterprises. J. Oper. Manag. 2004, 22, 265-289. [CrossRef]

41. Chung, S.Y.; Chin, S.; JingHaider, J.J.; Peter, B. The effect of green supply chain management on green performance and firm competitiveness in the context of container shipping in Taiwan. Transp. Res. Part E Logist. Transp. Rev. 2013, 55, 55-73.

42. Zhu, Q.; Sarkis, J.; Cordeiro, J.J.; Lai, K.H. Firm-level correlates of green supply chain management practices in Chinese context. Int. J. Manag. Sci. 2008, 36, 577-591. [CrossRef]

43. Chung, C.J.; Wee, H.M. Green component life cycle values on designed and reverse manufacturing in semi-closed supply chain. Int. J. Prod. Econ. 2008, 113, 528-545. [CrossRef]

44. Yeh, W.C.; Chuang, M.C. Using multi objective genetic algorithm for partner selection in green supply chain problem. J. Expert Syst. Appl. 2011, 38, 4244-4253. [CrossRef]

45. Saif, A.; Elhedhli, S. Cold supply chain design with environmental considerations: A simulation-optimization approach. Eur. J. Oper. Res. 2016, 251, 274-287. [CrossRef]

46. Bhateja, A.K.; Babbar, R.; Singh, S.; Sachdeva, A. Study of green supply chain management in the Indian Manufacturing industry: A literature review cum an Analytical Approach for the measurement of performanc. Int. J. Comput. Eng. Manag. 2011, 13, 84-99.

47. Toke, L.K.; Gupta, R.C.; Dandekar, M. An empirical study of green supply chain management in Indian perspective. Int. J. Appl. Sci. Eng. Res. 2012, 2, 372-383.

48. Sharma, V.; Chandna, P.; Bhardwaj, A. Green supply chain management related performance indicators in Agro industry: A Review. J. Clean. Prod. 2017, 141, 1194-1208. [CrossRef]

49. Aliahmadi, A.; Sadeghi, M.E.; Nozari, H.; Jafari-Eskandari, M.; Najafi, S.E. Studying Key Factors to Creating Competitive Advantage in Science Park. In Proceedings of the Ninth International Conference on Management Science and Engineering Management, Advances in Intelligent Systems and Computing, Berlin, Germany, 21-23 July 2015; pp. 977-987.

50. Chen, S.J.; Hwang, C.L.; Hwang, F.P. Fuzzy Multiple Attribute Decision Making Methods and Applications; Springer: New York, NY, USA, 1992.

51. Zadeh, L. Fuzzy sets. Inf. Control 1956, 8, 338-353. [CrossRef]

52. Opricovic, S.; Tzeng, G.H. Defuzzification within a multicriteria decision model. Int. J. Uncertain. Fuzziness Knowl. Based Syst. 2003, 11, 635-652. [CrossRef]

53. Mikhailov, L. Deriving priorities from fuzzy pairwise comparison judgements. Fuzzy Sets Syst. 2003, 134, 365-385. [CrossRef]

54. Mikhailov, L. A Fuzzy Programming Method for Deriving Priorities in the Analytic Hierarchy Process. J. Oper. Res. Soc. 2000, 51, 341-349. [CrossRef]

(C) 2019 by the authors. Licensee MDPI, Basel, Switzerland. This article is an open access article distributed under the terms and conditions of the Creative Commons Attribution (CC BY) license (http://creativecommons.org/licenses/by/4.0/). 